\title{
De Rerum Natura: \\ A ORIGEM DA LINGUAGEM E \\ DA CIVILIZAÇÃo NO LIVRO 5, \\ V.925-1240, DE LUCRÉCIO
}

Raquel Goes Casini*

\begin{abstract}
RESUMO
0 presente artigo foi desenvolvido durante a pesquisa de Iniciação Científica realizada na Faculdade de Filosofia, Letras e Ciências Humanas da Universidade de São Paulo com o apoio do CNPq. A pesquisa teve como objetivo o estudo e a análise dos versos 925-1240 do Livro 5 da obra De Rerum Natura de Tito Lucrécio Caro. Tal recorte apresenta principalmente a origem da linguagem e da civilização. Para o desenvolvimento desse artigo, com base na frequência do curso Lingua e Letteratura Latina II, na universidade La Sapienza, no ano de 2018, no texto latino publicado em Deufert (2019), nos comentários de Costa (1984), Bailey (1962), e outras análises poéticas da obra lucreciana, foi realizado um estudo do texto latino, sobretudo dos pontos de vista genérico e poético.
\end{abstract}

Palavras-chave: De rerum natura, Lucrécio, Linguagem.

\begin{abstract}
This article was developed during the Scientific Initiation research carried out at the The Faculty of Philosophy, Languages and Human Sciences of the University of São Paulo with the support of
\end{abstract}

* ORCID iD https://orcid.org/0000-0003-2670-1852. Faculdade de Filosofia, Letras e Ciências Humanas - Universidade de São Paulo. Graduada em Letras Português - Italiano na FFLCH-USP em 2021 após estudos científicos realizados no Brasil, no departamento de Letras Clássicas e Vernáculas da FFLCH-USP, e na Itália, no departamento de Letras Clássicas da Università La Sapienza.

E-mail: raquelcasini1@gmail.com .

Revista Páginas de Filosofia, v. 10, n. 1, p.5-32, jan.-jun. 2021 
CNPq. The research aimed to study and analyze verses 925-1240 of Book 5 of De Rerum Natura by Tito Lucrécio Caro. This article presents mainly the origin of language and civilization. To this end, based on the frequency of the Lingua e Letteratura Latina II course, at La Sapienza University, in 2018, in the Latin text published in Deufert (2019), in the comments of Costa (1984), Bailey (1962), and others poetic analyzes of the lucretian poetry, a study of the Latin text was carried out, especially from a generic and poetic point of view.

Keywords: De rerum natura, Lucretius, Language.

\section{INTRODUÇÃo}

Lucrécio viveu provavelmente no século I a.C $\mathrm{C}^{1}$ e foi um importante autor para a poesia latina ao influenciar diversos escritores posteriores não apenas no campo da poesia épica didática, mas também da filosofia antiga e moderna. Sabe-se pouco sobre sua vida, já que boa parte das informações a respeito dela apresenta-se na obra de São Jerônimo², escrita muitos anos após sua morte. No entanto, sua importante obra De rerum natura, daqui em diante $D R N$, relida e relembrada há centenas de anos, chegou integralmente aos dias de hoje por meio de fontes filológicas diretas e indiretas.

A épica filosófica e didática ${ }^{3}$ de Lucrécio é dividida em 6 grandes livros e tem como principal objetivo explicar em língua latina a doutrina epicurista e os fenômenos da natureza do início ao fim do universo. $D R N$ é uma poesia didática etiológica ${ }^{4}$, escrita em haxâmetro datílico ${ }^{5}$,

1 SMITH, Martin Ferguson (Com.). On the nature of things. Translated with introduction and notes by Martin Ferguson Smith. Oxford: Hackett Publishing Company, 2001. 10 p.

2 Ibid., p.vii

3 "Poesia didática [...] é o termo ainda hoje utilizado para designar não só a matéria [...] filosófica de Lucrécio. Seja a terra, sejam estrelas, seja a filosofia, 'canta-se' para ensinar o que é digno de saber. Mas encontram-se alternativas taxonômicas. [...]. Outra solução mais recente foi o termo 'didatic epic', [...] os poemas em tela não deixam de ser didáticos, nem deixam de ser épicos.” (OLIVA NETO, 2013, p. 43).

4 HARDIE, Philip. Lucretian multiple explanations and their reception in latin didatic and epic. In: BERETTA, Marco; CITTI, Francesco (Org.). La natura e la scienza. Firenze: Leo S. Olschki, 2008. 69 p.

5 Metro característico da poesia épica usado na épica grega e latina e tem como organização sonora o seguinte esquema: - vv / - vv / - vv / - vv / - vv / - v. 
que narra diversas origens, como a formação do universo, a natureza do átomo ${ }^{6}$, o início de uma sociedade civil ${ }^{7}$, o colapso trazido pela peste ${ }^{8} \mathrm{e}$ outros pontos considerados de extrema importância para a história da ciência, da filosofia e da poesia. Além do aspecto científico presente no poema, Lucrécio também explica em léxico latino temas discutidos pela filosofia epicurista, como a questão antiteleológica e o medo da morte.

A figura da Natura é central seja no título seja na obra como um todo e em cada um dos livros exerce um papel fundamental ao lado da religio, que na presente obra pode ser geralmente compreendida e traduzida como religião ou, em modo mais adequado aos ensinamentos de Lucrécio doutrina filosófica, como nos versos 931-934 do Livro 1:

primum quod magnis doceo de rebus et artis religionum animum nodis exsolvere pergo, deinde quod obscura de re tam lucida pango carmina musaeo contigens cuncta lepore. ${ }^{9}$

A doutrina de Epicuro é a grande resposta de Lucrécio para as questões filosóficas e científicas colocadas em todo o decorrer de $D R N$, e sua missão é o esclarecimento e a tentativa de uma explicação da doutrina filosófica epicurista em língua latina. Tal missão aparece de forma clara já no início do primeiro livro, v. 136-9, em que os desafios impostos ao poeta estão ligados diretamente à linguagem:

Nec me animi fallit Graiorum obscura reperta difficile inlustrare Latinis versibus esse, multa novis verbis praesertim cum sit agendum propter egestatem linguae et rerum novitatem ${ }^{10}$

6 Matéria narrada no Livro 1 de $D R N$.

7 Matéria narrada no Livro 5 de $D R N$.

8 Matéria narrada no Livro 6 de $D R N$.

9 "primeiro porque instruo acerca das grandes coisas e busco / com as artes libertar o ânimo dos nós das religiões, / daí porque de obscura coisa eu fixo tão lúcidos / cantos, tocando tudo com a graça de musa." (MAIA JUNIOR; VIEIRA; ALMEIDA, 2016, p. 59).

10 "E também não ignoro que é bem difícil explicar em versos latinos as obscuras descobertas dos gregos, sobretudo porque se faz mister empregar palavras novas, dada a pobreza da língua e a novidade da língua.» (PESSANHA, 1985, p. 33).

Revista Páginas de Filosofia, v. 10, n. 1, p.5-32, jan.-jun. 2021 
Lucrécio claramente usa Epicuro como modelo para sua criação, no entanto sua criação é poética e exposta em hexâmetro. Lucrécio assume o desafio de transpor tal doutrina filosófica e científica em léxico latino e na métrica característica da poesia épica. Uma das passagens mais conhecidas da obra que trabalha a relação muito própria entre filosofia e linguagem poética são os versos 926-950 do livro 1, quase idênticos aos versos 1-25 do livro 4. Repleto de imagens poéticas calimaquianas e helenísticas, o trecho mostra a importância das musas, como representação da poesia, para a possibilidade de execução de tal fazer poético. Um pequeno recorte do trecho citado que demonstra tal tradição poética na qual o texto lucreciano está inserido são os versos 945-950 do livro 1:

volgus abhorret ab hac, volui tibi suaviloquenti

carmine Pierio rationem exponere nostram

et quasi musaeo dulci contingere melle

si tibi forte animum tali ratione tenere

versibus in nostris possem dum perspicis omnem

naturam rerum qua constet compta figura. ${ }^{11}$

Ainda que o último verso da presente passagem apresente uma diferença entre o livro 1 e o livro $4^{12}$, é aqui que Lucrécio demonstra sua intenção de tornar mais doce e clara a doutrina de seu mestre Epicuro. Muito próxima a essa passagem está o trecho que relaciona o mel das musas e sua poesia com uma espécie de facilitação para a matéria posta em dificuldade, como a célebre passagem do livro 1, versos 921-950, explicada por Piazzi (2011, p. 7), Lucrécio se coloca como pioneiro ao escrever um poema filosófico em língua latina e explicita a imagem dos soavi licor, ao amaciar e de certa forma facilitar os ensinamentos filosóficos do mestre Epicuro por meio da poesia e do doce mel das Musas.

\footnotetext{
11 "o vulgo se horroriza dela, eu quis expor a ti com/ suaviloquente canto piério a nossa doutrina / e como que cobrir de mel o doce da musa, / se por acaso eu puder conter-te o ânimo com tal doutrina / em nossos versos, enquanto percebes toda/ a natureza das coisas de onde consta sua figura composta." (MAIA JUNIOR; VIEIRA; ALMEIDA, 2016, p. 60).

12 naturam rerum qua constet compta figura no livro 1, verso 950; naturam rerum ac persentis utilitatem no livro 4, verso 25.
} 
Sabe-se que Epicuro condenava a poesia, sobretudo a poesia homérica, segundo PIAZZI (2011 p. 17), o que demonstra certa diferença por parte de Lucrécio com relação ao modo escolhido para a exposição da doutrina epicurista. Ainda que seja uma matéria científica e filosófica, o texto lucreciano é claramente uma poesia e seus elementos compõem a tradição poética da épica didática que o sucede, sendo ele um grande modelo para Virgílio, nas Geórgicas, e para Manílio, nas Astronômicas.

Lucrécio então não se afasta de Epicuro ao fazer poesia, apenas se diferencia dele, pois, segundo Piazzi (2011, p. 18), a explicitação da doutrina por meio da poesia não se afasta completamente de Epicuro, uma vez que "a glória perene que aspira Lucrécio, ao conquistá-la com a poesia, coincide com a mesma gloria que possui Epicuro, e se reverbera sobre a doutrina do mestre ${ }^{13}$ ".

A escolha de Lucrécio ao escrever um poema didático não anula sua exposição clara, em língua latina, da doutrina filosófica de Epicuro e o torna também distinto da tradição poética precedente justamente por carregar a matéria epicurista em seus versos e por explicar matérias até então pouco conhecidas e pouco explicadas em latim e mesmo em grego ${ }^{14}$. Sua proximidade com a doutrina epucurista é, segundo Trezza, (1994, p. 7), a busca de explicações para os fenômenos naturais de modo racional e a explicitação de um contraste com a tradição popular anterior a Lucrécio.

$D R N$ é repleta de detalhes que relacionam diversas fontes, como Homero e Ênio, além de ser modelar para poetas latinos posteriores como Virgílio e Horácio ${ }^{15}$ não apenas na épica didática, mas em outros gêneros explorados pela poesia latina através dos tempos. Muitas formas usadas por Lucrécio em toda a obra remetem a Ênio, importante antecessor helenístico, e à poesia helenística em geral, segundo SMITH

13 “[...] la gloria perenne cui L. aspira, da conquistarsi con la poesia, coincide con la medesima gloria di cui gode Epicuro, e si riverbera sulla dottrina del Maestro."

14 SMITH, Martin Ferguson (Com.). On the nature of things. Translated with introduction and notes by Martin Ferguson Smith. Oxford: Hackett Publishing Company, 2001. $11 \mathrm{p}$.

15 "Lucr.'s account was also followed by Virgil (AEN viii 314-18) and by Horace (SAT. i.3. 99-106), both of whom in their earlier life came under the influence of Epicureanism."(BAILEY, 1962, p. 1473).

Revista Páginas de Filosofia, v. 10, n. 1, p.5-32, jan.-jun. 2021 
(2001, p. x). 0 modelo poético é claramente helenístico e Epicuro serve de modelo filosófico para todos os 6 livros escritos por Lucrécio.

As diversas temáticas abordadas em $D R N$ fazem parte de uma proposta de explicação científica e não teológica para a época visando encontrar respostas jamais obtidas anteriormente. Tal proposta é chamada pela crítica de doutrina antiteleológica, ponto central para todo o desenvolvimento do poema e explicado com mais detalhes no livro $1 \mathrm{em}$ passagens como os versos 82-94, com o sacrifício de Ifigênia que exemplifica o papel da religio e a influência pouco positiva que ela exerce na vida dos homens. Segundo Trezza (1994, p. 27), com essa passagem "ele deseja demonstrar que aquela superstição (religio) que decide combater conduzia frequentemente a cega e crente humanidade aos crimes mais perversos"16, como faz Agamemnon ao levar a própria filha para uma condenação à morte a fim de seguir corretamente os preceitos religiosos.

Diversas áreas do conhecimento são abordadas em $D R N$ e com explicações muito presentes no decorrer da história das ciências e da literatura. A doutrina antiteleológica aparece em diversos pontos do poema por meio das explicações cosmológicas, fisiológicas e psicológicas; e Lucrécio oferece explicações para fenômenos ligados à raça humana, como o sono, o amor e a própria linguagem e também detalha fenômenos cósmicos e naturais como as estações, o vento, a chuva e tantos outros movimentos característicos da Natura. Segundo Fabbri (1997, p. 83), "coisas de que a ciência, ainda na sua infância, da época de Lucrécio estava longe de poder dar uma explicação que não fosse fantástica ou absurda".

Ainda que cientificamente muitas questões descritas por Lucrécio tenham sido respondidas, sua contribuição para a história das ciências e da filosofia é inestimável, sendo $D R N$ um modelo para cientistas de diversos períodos históricos como os atomistas ${ }^{17}$ e os humanistas ${ }^{18} \mathrm{e}$

16 "Egli vuole [...] dimostrare che quella superstizione (religio), che ha preso a combattere, indusse bene spesso l'umanità cieca e credenzona ai più empi misfatti."

${ }^{17}$ PIAZZI, Lisa. Atomismo e polemica filosofica: Lucrezio e i presocratici. In: BERETTA, Marco; CITTI, Francesco (Org.). La natura e la scienza. Firenze: Leo S. Olschki, 2008. $11 \mathrm{p}$.

18 CITTI, Francesco. Pierio recubans Lucretius antro: Sulla fortuna umanistica di Lucrezio. In: BERETTA, Marco; CITTI, Francesco (Org.). La natura e la scienza. Firenze: Leo S. Olschki, 2008. 97 p. 
também um modelo filosófico para a tradição epicurista através dos tempos. E além de contribuições puramente científicas, DRN permanece na tradição poética, e posteriormente literária, de diversas maneiras, desde a poesia de latina augustana até a literatura do século XX. A obra de Lucrécio, por exemplo, é referência importante para Italo Calvino, em sua obra Seis propostas para o próximo milênio:

De rerum natura, de Lucrécio, é a primeira grande obra poética em que o conhecimento do mundo se transforma em dissolução da compacidade do mundo, na percepção do que é infinitamente minúsculo, móvel e leve. [...] A poesia do invisível, a poesia das infinitas potencialidades imprevisíveis, assim como a poesia do nada, nascem de um poeta que não nutre qualquer dúvida quanto ao caráter físico do mundo. (CALVINO, 1990, p. 20-21)

A referência de $D R N$ em Calvino é a representação da leveza, já que o poeta trata de explicar por meio da poesia as questões ainda incompreensíveis para a ciência de sua época e ao mesmo tempo faz poesia e filosofia em sua épica didática permanecendo assim na tradição literária.

Dentre todos os complexos temas presentes em $D R N$, é de especial importância para a redação do presente artigo um importante trecho do livro 5, uma das primeiras fontes com uma longa e complexa descrição sobre a origem da linguagem em seus primeiros usos e sobre a natureza da civilização humana desde seus primórdios. Tal trecho, versos 925-1240 do Livro 5, demonstra detalhadamente o fazer poético e filosófico de Lucrécio e traz reflexões importantes ainda atualmente sobre o modo em que a linguagem e o comportamento humanos eram entendidos pelos antigos.

\section{LIVRO 5}

O quinto livro da obra de Lucrécio trata sobre os fenômenos do mundo em suas respectivas formações e desenvolvimentos e descreve a vida na terra como um todo, passando por importantes descrições sobre a vida vegetal e animal e posteriormente para a vida humana em seus primórdios e de que modo a raça humana passou a se orga- 
nizar como civilização e sociedade. O livro se inicia com um elogio a Epicuro e logo em seguida é apresentada uma breve descrição da matéria que será narrada durante todo o livro 5. Bailey (1962, p. 1320 ) considera que o "livro 5 trata, grosso modo, da cosmogonia em geral e de nosso mundo ${ }^{19}$ ".

Nessa perspectiva, Lucrécio apresenta uma espécie de introdução da matéria que será narrada posteriormente por seus hexâmetros e o excerto a seguir serve de exemplificação desse proêmio, v. 66-76:

et quibus ille modis congressus materiai fundarit terram caelum mare sidera solem lunaique globum tum quae tellure animantes extiterint et quae nullo sint tempore natae quodve modo genus humanum variante loquella coeperit inter se vesci per nomina rerum et quibus illemodisdivommetusinsinuarit pectora terrarum qui in orbi sancta tuetur fana lacuslucos aras simulacraquedivom praeterea solis cursus lunaeque meatus expediam qua vi flectat natura gubernans [...] ${ }^{20}$

Cada um dos argumentos introduzidos por essa passagem é apresentado no livro 5 de forma descritiva e posteriormente mais detalhada ao longo do poema. 0 início relaciona-se diretamente com Epicuro, como nos versos 66-68, que dizem respeito ao atomismo e à composição da matéria ${ }^{21}$ A seguir, nos versos 66-67, introduz-se a raça humana e posteriormente sua capacidade linguística em comparação

19 "Book v treating, roughly speaking, of cosmogony in general and of our world [...]" 20 "[...] tenho de explicar a razão de ser o mundo composto de uma substância mortal e estar submetido às leis do nascimento. Direi também de que modo esse agregado de matéria formou a Terra, o céu, o mar, as estrelas, o Sol e o globo da Lua; depois que seres vivos nasceram da terra e quais os que nunca nasceram, e de que modo a raça humana começou a estender-se entre si uma linguagem variada por meio de nomes dados às coisas; e de que modo se insinuou nos peitos aquele medo aos deuses que em todo o orbe das terras protege os templos sagrados, os lagos, os bosques, os altares e as imagens dos deuses." (PESSANHA, 1985, p. 98).

21 COSTA, C.D.N. (Org.). De rerum natura V. Edited with introduction and commentary by C.D.N. Costa. Oxford: Clarendon Press, 1984. 56 p. 
aos outros animais. Outros elementos são enumerados, sendo respectivamente: o medo ${ }^{22,}$ v. $72-73$, as mudanças graduais do homem e da natureza, v. 73-74, os movimentos astronômicos, v. 75, e ainda, nos versos seguintes, a organização civil e a capacidade poética e filosófica, matéria tratada já na parte final do livro 5 .

Bailey (1962, p. 1320) considera que o livro 5 foi escrito antes dos livros 3 e 4 e que representa uma porção essencial do poema lucreciano por tratar diretamente do mundo terreno e humano. Uma descrição pioneira da composição social do homem é realizada por Lucrécio e a relação do homem com outros animais nos primórdios da organização social são pontos importantes para a compreensão do mundo segundo os antigos. As descrições lucrecianas são baseadas na filosofia epicurista e também em outras fontes filosóficas gregas. Platão e os helenísticos servem de base para uma descrição filosófica realizada por Lucrécio, certamente datada do ponto de vista científico, mas atemporal do ponto de vista poético e filosófico.

\section{RECORTE - V. 925-1240}

Os versos 925-1240 do livro 5 de $D R N$ tratam principalmente da origem da linguagem e da civilização, da relação que os homens primitivos possuíam com a comunicação e de que modo a raça humana nômade passou a se organizar como sociedade. A matéria é introduzida no início do livro 5, v. 66-67, e a descrição de Lucrécio nos versos do recorte trata-se de uma importante ekphrasis a respeito do tema por emular e dialogar com outras tradições da épica didática referentes à origem do homem, como Hesíodo, em grego, Virgílio, Ovídio e Manílio, em latim. Parte de tal matéria já é descrita brevemente pelo mestre Epicuro na Carta a Heródoto (73-6) e, ademais, segundo Bailey (1962, p. 1320-1321) "as razões para o estudo da cosmologia estão claramente indicadas na Carta a Heródoto (76-82) e são panos (seria pano?) de fundo implícitos deste livro [5]".

22 Tal passagem de Lucrécio possui uma perspectiva ligeiramente diferente daquela apresentada por Epicuro, pois Lucrécio descreve a gradual mudança do mundo e do homem como positivas e o que possui um poder destrutivo é o medo. Tal momento dialoga também com o livro III, v. 830-869, em que Lucrécio descreve a morte como natural e coloca a própria natureza, em um discurso direto, a argumentar contra um desejo humano de prolongar a existência. (MILANESE, 2014, p.xxv).

Revista Páginas de Filosofia, v. 10, n. 1, p.5-32, jan.-jun. 2021 
Após sua descrição sobre a origem da vida vegetal e animal, Lucrécio inicia uma clara descrição sobre a origem da vida humana e dos comportamentos primitivos da humanidade antes e depois de um certo início de organização social. Tal descrição é apresentada de modo detalhado, estendo-se (seria, estendendo-se?) do verso 925 ao 1010, e pode ser dividida em diversos pontos, como a descoberta do fogo, o uso de vestes, a origem da linguagem e a importância para o convívio entre humanos. Após tal passagem, a civilização começa seu desenvolvimento que é largamente descrito do verso 1011 ao 1457, que também pode ser dividido em diversos pontos importantes, como a relação da sociedade primitiva com a religião e as práticas religiosas realizadas pelos homens aos deuses, bem como o impacto de tais práticas na organização social segundo os antigos, além da capacidade política, poética e filosófica.

Já no verso 925, após as descrições lucrecianas a respeito do mundo vegetal, a espécie humana é apresentada por meio de uma imagem bucólica, primitiva ao ser descrita nos campos, in arvis. A $\mathrm{Na}$ tura aparece também como jovem e capaz de proporcionar um locus amoenus a uma também jovem raça humana, v. 937-938:

quod sol atque imbres dederant quod terra crearat sponte sua satis id placabat pectora donum. ${ }^{23}$

A descrição bucólica relacionada ao espaço pertencente a essa raça humana jovem segue nas descrições por meio de figuras como glandiferas quercus, bolotas de carvalho, v. 938, e de situações naturais como o amadurecimento dos frutos ${ }^{24}$.

Tal descrição poética remete a uma novidade do mundo em que o homem está ao lado de uma Natura ainda jovem, fértil e abundante ${ }^{25}$,

${ }^{23} 0$ que o sol e as chuvas haviam dado, aquilo que a terra havia criado / por sua espontaneidade, frequentemente esse presente acalmava-lhes o coração. (Todas as traduções do recorte comentado no presente artigo foram realizadas pela autora do presente artigo).

${ }^{24}$ arbita puniceo fieri matura colore (os frutos do medronheiro tornam-se maduros e de cor vermelha. v. 941).

${ }^{25}$ multaque praeterea novitas tum florida mundi / pabula dura tulit, miseris mortalibus ampla. v. 943-4 (Depois isso, então, a abundante, florida juventude do mundo / produzia resistentes alimentos, abundantes aos pobres mortais.). 
desconhecendo a ars e as diversas técnicas de trabalho com a terra. A espécie humana é descrita como nômade, por meio do termo volgivago, v. 932, e claramente o trabalho agrícola, muito explorado pela poesia didática posteriormente, nas Geórgicas, por exemplo, ainda era desconhecido, já que não havia nenhum robusto condutor do curvo arado ${ }^{26}$. A humanidade não sabia trabalhar os campos com ferro ${ }^{27}$, fazer plantações de novos arbustos $^{28}$ ou podar árvores ${ }^{29}$ e todo o consumo de alimentos era fornecido pela própria Natura e pela própria terra. A geração de frutos e da fertilidade do solo era gerada espontaneamente, sponte sua, pela terra e essa descrição de uma Idade do Ouro ${ }^{30}$, tradicional de acordo com a tradição grega, mantém a ideia de espontaneidade da terra, do sol e das chuvas ${ }^{31}$.

Os costumes dessa jovem raça humana são descritos já no verso 932, pois conduziam a vida à maneira de feras ${ }^{32}$ e seus comportamentos estavam diretamente relacionados à Natura. A abundância de juventude e fertilidade aparece ao lado da farta umidade a partir do verso 945, em que as imagens usadas na descrição remetem sempre a um movimento e a uma sensação ligados diretamente à água, como sitientia ${ }^{33}$, umore fluenta ${ }^{34}$ e a repetição do sintagma umida saxa próximos ao particípio presente stillantia nos versos 950-952:

lubrica proluvie larga lavere umida saxa, umida saxa, super viridi stillantia musco, et partim plano scatere atque erumpere campo ${ }^{35}$

\footnotetext{
${ }^{26}$ nec robustus erat curvi moderator aratri v. 933.

${ }^{27}$ quisquam, necscibat ferro molirier arva v. 934.

${ }^{28}$ nec nova defodere in terram virgultaneque altis v. 935.

${ }^{29}$ arboribus veteres decidere falcibus ramos v. 936.

30 Período esse caracterizado pela paz entre os homens em suas primeiras organizações sociais, narrada por Hesíodo, na poesia, e por Empédocles, na filosofia e presente em tantas outras obras que compõem a tradição clássica grecolatina.

31 quod sol atque imbres dederant, quod terra crearat v. 937. 0 que o sol e as chuvas haviam dado, aquilo que a terra havia criado.

32 [...] vitam tractabant more ferarum. v. 932.

${ }^{33}$ claricitat late sitientia saecla ferarum. (convida amplamente para que não sintam sede as gerações de feras.).

34 [...] quibus e scibant umore fluenta (a partir dos quais sabiam que, com a abundante inundação).

35 terrenos com largos fluxos banhavam úmidos rochedos e / úmidos rochedos, sob o verdejante musgo gotejando / e que em parte era cheia e brotava sobre a nivelada planície.
} 
Além da juventude da terra e da ausência de técnica para o trabalho agrícola, a humanidade ainda não possuía conhecimento necessário para o manuseio do fogo para se aquecer ou para o uso de roupas, v. 953-954:

necdum res igni scibant tractare neque uti pellibus et spoliis corpus vestire ferarum ${ }^{36}$

Suas casas são descritas como rudimentares, selvagens ${ }^{37}$, e sua aparência como suja ${ }^{38}$. Essa descrição primitiva mostra uma ausência da sociedade civil em que os seres humanos não podiam contemplar o bem comum ${ }^{39}$ e existia apenas uma organização com base na fortuna, sorte, v. 960-961 e o mais importante era o bem estar individual:

quod cuique obtulerat praedae fortuna ferebat sponte sua sibi quisque valere et vivere doctus. ${ }^{40}$

E é nessa falta de organização civil que, com a graça de Vênus, ocorre a procriação. É interessante ressaltar que a figura de Vênus é a abertura do livro 1 de $D R N^{41}$ e possui uma relação direta com a Natura durante toda a obra. A fortuna crítica a respeito de Lucrécio relaciona a figura de Vênus a pontos importantes, como no livro 3, v. 581-660, em que Magna Mater é descrita e louvada em moldes semelhantes aos de Vênus no proêmio do livro 1. Aqui, no entanto, por tratar-se ainda de uma sociedade rudimentar, Vênus aparece como representação do instinto animal e da procriação, mais próxima da descrição apresentada no decorrer do livro 4, segundo Milanese (2014, p. xxv), com relação ao sexo e ao instinto, e não ao amor. A raça humana é descrita como ainda primitiva e em cada descrição aparece ao lado dos animais:

\footnotetext{
${ }^{36}$ Ainda não sabiam transformar coisas com o fogo, nem usar / peles e vestir o corpo com espólios de animais.

${ }^{37}$ sed nemora at que cavos montis silvasque colebant (mas habitavam profundos bosques, montes e selvas).

${ }^{38}$ squalida membra v. 955.

${ }^{39}$ commune bonum v. 958.

${ }^{40}$ Pois o que a sorte oferecera a cada um é a presa à caça / pela própria espontaneidade, e cada um estava habituado a viver para si e ser forte.

41 v. $1-62$.
}

Revista Páginas de Filosofia, v. 10, n. 1, p.5-32, jan.-jun. 2021 
O jogo do amor é representado com drástica violência; não há lugar para o doce vínculo familiar; na floresta eles comandam apenas, em termos de amor, ou o cupido mútuo do homem e da mulher, ou a arrogância viril feroz, ou um presente da rústica cavalaria selvagem como bolotas de medronheiro, peras selecionadas ${ }^{42}$.

Com tal menção quase literal ao significado das palavras citadas nos versos 963-965, Fabbri (1997, p. 231) afirma que o amor também possui um caráter rudimentar para essa jovem raça humana.

A caça também aparece como elemento rústico e característico da raça humana, em destaque desde o verso $926^{43}$, assim como a ideia de força física. 0 homem, então realizava a caça das selvagens gerações de feras ${ }^{44}$ e suas armas eram também demonstração de pouca técnica, como lanças, pedras e um pesado bastão ${ }^{45}$. No entanto, algumas vezes, a caça e a vitória diante da presa davam lugar ao rude esconderijo de folhagens e galhos em busca de proteção:

multaque vincebant, vitabant pauca latebris; saetigerisque pares subus silvestria membra nuda dabant terrae nocturno tempore capti, circum se foliis ac frondibus involventes ${ }^{46}$.

Então, desde muito jovens, os homens encontravam-se mais próximos da natureza e, segundo Bailey (1962, p. 1474), “os homens não temiam a noite, mas buscavam naturalmente a sucessão da noite e do dia (973-81), ponto em que Lucrécio coloca considerável ênfase."

42 "Il gioco d'amore è rappresentato con drastica violenza; non c'è luogo per il dolce vincolo familiare; nelle selve comandaano solo, in fatto di amore, o la cupido reciproca dell'uomo e della donna, o la feroce prepotenza virile, o un dono di selvaggia rusticana cavalleria come ghiande corbezzoli, pere scelte."

43 durius, ut decuit, tellus quod dura creasset (e em modo mais forte, visto que foi conveniente, pois a terra a teria criado forte).

${ }^{44}$ silvestria saecla ferarum v. 966.

${ }^{45}$ missilibus saxis et magno pondere clavae. (com lanças, pedras e o grande peso do bastão).

${ }^{46}$ Muitas venciam e poucas evitavam em esconderijos / semelhantes aos eriçados javalis, os selvagens membros / nus mantinham na terra, escondidos durante a noite / cobrindo-se, envolvidos entre as folhagens e os galhos.

Revista Páginas de Filosofia, v. 10, n. 1, p.5-32, jan.-jun. 2021 
A raça humana primitiva era descrita por Lucrécio como uma raça humana feliz sobretudo pela simplicidade de seus desejos e pela relação direta com a natureza.

A proximidade entre a Natura e a humanidade não era baseada na compreensão dos fenômenos naturais por parte dos homens, mas no hábito e no costume. Com relação aos fenômenos da natureza, nota-se a alternância entre o dia e a noite como um fato certo e corriqueiro para os homens primitivos e, além disso, a possibilidade de que fossem surpreendidos por fenômenos não usuais era pequena de acordo com o texto lucreciano, versos 977-979:

a parvis quod enim consuerant cernere semper

alterno tenebras et lucem tempore gigni

non erat ut fieri posset mirarier umquam ${ }^{47}$

A vida dos homens nesse período era, no entanto, diferente das demais descrições da Idade do Ouro, pois Lucrécio, segundo Bailey (1962, p. 1473), quebra com as tradições anteriores de uma Idade do Ouro primitiva, "aceita pelos pitagóricos, e com a imagem mais modificada dada por Empédocles e amplamente adotada por Platão, que descreve como os homens viviam uma vida simples em amizade uns com os outros e os animais." Em Lucrécio, a relação da raça humana com os animais não era descrita sempre de modo harmônico e a convivência não se dava de forma pacífica com as gerações de feras, pois tais feras frequentemente tornavam perigosa a paz dos pobres homens ${ }^{48}$. Do verso 984 ao 987 é apresentada uma descrição clara dessa convivência pouco pacífica entre as feras e os homens primitivos, sempre repleta de elementos rudimentares, como ataques repentinos de javalis raivosos ${ }^{49}$ e leitos cobertos de folhas ${ }^{50}$.

\footnotetext{
${ }^{47}$ Desde jovens, então, tinham estado sempre acostumados a distinguir / que a luz e as trevas eram produzidas em um tempo alternado, / não havia algo que pudesse surpreendê-los de algum modo

${ }^{48}$ infestam miserisfaciebantsaepe quietem. v. 983.

${ }^{49}$ spumigeri suis v. 985.

${ }^{50}$ instrata cubilia fronde v. 987.
}

Revista Páginas de Filosofia, v. 10, n. 1, p.5-32, jan.-jun. 2021 
Lucrécio segue, então, com uma descrição detalhada das mudanças humanas em que para uma humanidade ainda jovem já existe o medo da morte, sendo a morte uma representação do desconhecido ${ }^{51}$. A morte é descrita de forma violenta e proveniente de um ataque de feras, como nos versos 990 - 993:

unus enimtumquisque magis deprensus eorum pabula viva feris praebebat, dentibus haustus, et nemora ac montis gemitu silvasque replebat viva videns vivo sepeliri viscera busto. ${ }^{52}$

0 medo da morte aparece também de maneira clara nos versos 995-997 por meio de imagens violentas, como ulcera tetra ${ }^{53}$, horriferis vocibus ${ }^{54}$, Orcum $^{55}$ e vermina saeva ${ }^{56}$. A ideia de temor e morte segue presente também nos versos seguintes ao mencionar a importante relação entre a morte e a descoberta técnica da navegação:

at non multa virum sub signis milia ducta

una dies dabat exitio necturbida ponti

aequora lidebant navis ad saxa virosque. ${ }^{57}$

0 medo do mar e o medo do desconhecido permanecem ignorados pelos humanos, assim como o perverso conhecimento da navegação $0^{58}$. A Natura e a abundância passam a ser menos presentes na vida dos homens primitivos e a falta de alimento levava à morte os fracos mem-

51 Relação direta com o livro III versos 830-869.

${ }^{52} \mathrm{E}$ então um deles, descoberto com mais frequência / representava alimentos vivos para as bestas, devorados por seus dentes / e enchia bosques e montes e selvas com um grito, / vendo sua viva carne ser enterrada em uma viva tumba.

53 repulsivas feridas

54 com terríveis gritos

${ }^{55}$ Orco, Inferno.

56 terríveis convulsões

57 No entanto, nunca muitos milhares de homens eram conduzidos sob as insígnias / nem um único dia conduzia à morte ou as turvas águas / do mar arremessavam nas pedras os navios e os homens.

${ }^{58}$ improba navigii ratio tum caeca iacebat. v. 1006.

Revista Páginas de Filosofia, v. 10, n. 1, p.5-32, jan.-jun. 2021 
$\operatorname{bros}^{59}$. A harmonia descrita no início da humanidade dá lugar a uma ausência de abundância e de fertilidade a organização humana passa a ser descrita como uma civilização sedentária e os humanos passam a ser descritos como imprudentes, como nos versos 1009-1010:

illi inprudentes ipsi sibi saepe venenum vergebant, nunc dant [aliis] sollertius ipsi. ${ }^{60}$

A partir do verso 1011, são mencionadas as primeiras comunidades humanas e, nas palavras de Bailey (1962, p. 1483), "Lucrécio passa da vida aleatória do homem primitivo para os vários estágios da civilização, que ele continua a descrever no resto do livro ${ }^{61 . "} 0$ ser humano nômade passa a uma vida sedentária e o acaso dá lugar à lei e à organização social que cresce e se estabelece pouco a pouco.

Brevemente são descritas as relações dos humanos com o fogo não apenas para o aquecimento, mas com um desenvolvimento técnico visando o aquecimento. A passagem de uma organização nômade a uma organização sedentária, assim como o uso de vestes, são pontos importantes para essa sedentarização narrada por Lucrécio ${ }^{62}$. A raça humana, a partir dessa perspectiva, é descrita no verso 1014 como suave, sendo mollescere uma importante referência semântica presente em Oliva Neto (2013, p. 63) para o estudo genérico da poesia didática:

tum genus humanum primum mollescere coepit ${ }^{63}$

A organização social primitiva nasce, então, novamente a partir da figura de Vênus, mencionada diretamente no verso 1017, em posição de destaque:

\footnotetext{
${ }^{59}$ tum penuria deinde cibi languentia leto / membra [...] v. 1007-8.

${ }^{60}$ aqueles, imprudentes, em si mesmos frequentemente veneno / derramavam, agora eles oferecem aos outros com mais sagacidade.

61 "Lucr. passes away from the haphazard life of primitive man to the various stages of civilization, which he continues to describe for the rest of the book"

${ }^{62}$ Inde casas postquam ac pellis ignemque pararunt (Então depois prepararam casas, vestes e fogo) v. 1011.

63 então, a espécie humana primeiro começou a tornar-se suave
}

Revista Páginas de Filosofia, v. 10, n. 1, p.5-32, jan.-jun. 2021 
et Venus inminuit viris puerique parentum ${ }^{64}$

A vida familiar pouco a pouco se converteu em amizade dentro dessa sociedade primitiva e nota-se um "rudimentar 'contrato social' das famílias”, segundo Bailey, (1962, p. 1484), a partir do verso 1019:

tunc et amicitiem coeperunt iungere aventes

finitimi inter se nec laedere nec violari ${ }^{65}$

Nesse momento, a comunicação dos homens era ainda baseada em gestos e sons confusos ${ }^{66}$, mas grande parte da comunidade conservava a união ${ }^{67}$, ou então toda a raça humana já teria sido destruída ${ }^{68}$ e, segundo o próprio texto latino no verso 1027, e nem teria podido a descendência até aqui perdurar as gerações ${ }^{69}$.

Segundo as passagens citadas de $D R N$, a presença dessas duas características, a união civil e a linguagem, foram elementos suficientemente capazes de impedir a sociedade humana de uma eventual extinção. Tal característica está relacionada com os ensinamentos da doutrina filosófica de Epicuro, mas segundo Bailey (1962, p. 1484):

O principal ponto de contato com Epicuro aqui reside no terceiro estágio e na ideia da origem da justiça e da lei em um pacto "não prejudicar ou ser prejudicado" formado para benefício mútuo. Assim diz o próprio Epicuro: 'a justiça nunca é nada em si mesma, mas nas relações dos homens uns com os outros, em qualquer lugar e a qualquer momento, é uma espécie de pacto para não prejudicar ou ser prejudicado'. Em seu aspecto geral a justiça é puramente utilitária, [...] Ele enfatiza o amor familiar como fundamento da união, insiste no sentimento de piedade para com as mulheres e crianças, e, principalmente, sustenta (v. 1019) que o desejo de amizade foi uma das causas da formação do contrato.

\footnotetext{
${ }^{64}$ e Vênus diminuiu as forças e os meninos facilmente

${ }^{65} \mathrm{E}$ então os vizinhos começaram a formar uma amizade / desejando entre si não prejudicar nem ser violado

${ }^{66}$ vocibus et gestu cum balbe significarent v. 1022.

${ }^{67}$ sed bona magnaque pars servabat foedera caste $\mathrm{v} .1025$.

${ }^{68}$ aut genus humanum iam tum foret omne peremptum v. 1026.

${ }^{69}$ nec potuisset adhuc perducere saecla propago.
}

Revista Páginas de Filosofia, v. 10, n. 1, p.5-32, jan.-jun. 2021 
Ele não se revolta com a ideia epicurista, mas dá a ela um fundo mais natural e humano ${ }^{70}$.

Aqui, então, a descrição de Lucrécio enfatiza e detalha o aspecto humano do início da civilização e da origem da linguagem.

\section{A origem da linguagem em De rerum natura}

A partir do verso 1028, o poema apresenta uma longa ekphrasis sobre a origem da linguagem que relaciona diretamente $D R N$ às tradições filosóficas a respeito do tema, como a doutrina platônica apresentada principalmente nos diálogos Fedro e Crátilo ${ }^{71}$.

At varios linguae sonitus natura subegit

mittere et utilitasexpressit nomina rerum ${ }^{72}$,

A origem da linguagem é exposta por Epicuro em uma passagem da Carta a Heródoto onde o filósofo dá seu testemunho ao falar a respeito do crescimento da civilização e sobre as artes serem ensinadas pela Natura e, posteriormente, desenvolvidas pela razão. A passagem de Epicuro, traduzida para o inglês por Bailey (1962, p. 1487) e para o português por nós, apresenta-se da seguinte forma:

[...] nomes, também, não foram a princípio dados deliberadamente às coisas, mas as naturezas dos homens de acordo com suas diferentes

70 "The chief point of contact with Epicurus here lies in the third stage and in the idea of the origin of justice and law in a compact 'not to harm or be harmed' formed for mutual advantage. So Epicurus says himself: 'justice never is anything in itself, but in the dealings of men with one another in any place whatever and at any time it is a kind of compact not to harm or be harmed.' In its general aspect justice is purely utilitarian, [...] He emphasizes family love as the foundation of union, insists on the sentiment of pity for women and children, and, most notably of all maintains (1019) that the desire for friendship was one of the causes of the formation of the contract. He does not revolt from the Epicurean idea, but gives it a more natural and human background."

${ }^{71}$ COSTA, C.D.N. (Org.). De rerum natura V. Edited with introduction and commentary by C.D.N. Costa. Oxford: Clarendon Press, 1984. 119-120 p.

72 Mas os vários sons da língua a natureza incitou / a pronunciar e a utilidade expressou o nome das coisas 
nacionalidades tinham seus próprios sentimentos e impressões peculiares, de acordo com as diferenças mandadas nas diferentes nações pelos locais de sua residência como bem. E então, mais tarde, por consentimento comum em cada nacionalidade, nomes especiais foram deliberadamente dados a fim de tornar seus significados menos ambíguos e demonstrados de forma mais resumida. E às vezes aqueles que os conheciam traziam coisas até então desconhecidas e introduziam sons para eles, em algumas ocasiões sendo naturalmente constrangidos a pronunciá-los, em outras escolhendo-os pela razão de acordo com a analogia geral e, assim, eles deixavam claro seu significado. ${ }^{73}$

Em Epicuro aparece, então, a ideia de natura e de utilitas, como apresentados nos versos lucrecianos citados acima. No que diz respeito a Platão e a teoria mencionada anteriormente, Bailey (1962, p. 1489) comenta que tal diálogo ocupa-se da análise de nomes de deuses e Lucrécio não trata exatamente dos tipos de nomes apresentados em Platão, mas busca explicar a origem e o uso da linguagem pela raça humana primitiva.

Ao tratar sobre o início da linguagem, as descrições dos comportamentos humanos são sempre realizadas por meio de comparações com os animais e os meninos, pueros, no verso 1031. As crianças, então, têm seus comportamentos colocados ao lado das ações dos vitelos durante o nascimento dos chifres, uma situação nova que tende a desencadear uma agressividade nos pequenos, como nos versos 1034-5:

cornua nata prius vitulo quam frontibus extent, illis iratus petit atque infestus inurget. ${ }^{74}$

73 [...] names, too, were not at first deliberately given to things, but men's natures according to their different nationalities had their own peculiar feelings and impressions, according to the differences mande in the different nations by the places of their abode as well. And then later on by common consent in each nationality special names were deliberately given in order to make their meanings less amiguous to one another and more briefly demonstrated. And sometimes those who were acquainted with them brought in things hitherto unknown and introduced sounds for them, on some occasions being naturally constrained to utter them, on others choosing them by reason in accordance with general analogy and thus they made their meaning clear.

74 Ainda antes que os nascidos chifres tornem-se visíveis nas têmporas do vitelo / ele, irritado, com os chifres ataca e, hostil, é agressivo.

Revista Páginas de Filosofia, v. 10, n. 1, p.5-32, jan.-jun. 2021 
A dificuldade de comunicação é colocada ao lado das desagradáveis sensações dos jovens animais na idade de aprender a controlar seus próprios instintos e tais relações são apresentadas com exemplos de filhotes de gerações de panteras e leões, pantherarum e leonum, v. 1036, e de aves, alituum, v. 1039. A relação entre os meninos que aprendem a falar é comparada ao aprendizado de certos instintos como voar ou suportar o crescimento das garras por parte dos filhotes de animais.

Os versos 1041-1045 demonstram de modo quase sintético a origem da linguagem apresentada por Lucrécio em $D R N$ :

proinde putare aliquem tum nomina distribuisse rebus et inde homines didicisse vocabula prima, desiperest namcur hic posset cuncta notare vocibus et varios sonitus emittere linguae, tempore eodem alii facere id non quisse putentur? ${ }^{75}$

Em tal trecho fica claro que uma criação intencional da linguagem por parte do homem é uma possibilidade descartada por Lucrécio. Um só humano, ou um grupo de humanos, não seria capaz de criar e disseminar a linguagem de forma harmônica e plenamente compreensível. A teoria sobre a origem da linguagem segue até o verso $1090 \mathrm{com}$ exemplificações ligadas a diversos instintos por meio de referências a animais, como gado, pecudes, v. 1959, cães molossos, Molossum, v. 1063, cavalo, equus, v. 1074 e aves, alituum, v. 1078.

Bailey (1962, p. 1490) resume tal passagem a respeito da origem da linguagem e das etapas pelas quais ela passa de acordo com a poesia lucreciana:

A primeira é a reação quase física da voz às emoções e sensações ( $v a-$ rios linguae sonitus natura subegit mittere), que dá origem aos gritos elementares do bebê. Isso ele ilustra pelas tentativas de pássaros e animais de antecipar o uso de seus membros quase antes de serem desenvolvidos (1034-40). 0 segundo, que se desenvolve a partir dessa

75 Do mesmo modo, pensar que alguém então distribuiu nomes / às coisas, e que dali os homens aprenderam suas primeiras palavras / é tolo. Por que aquele poderia marcar tudo / com palavras e pronunciar os vários sons da língua e ao mesmo tempo não se julgaria que outros seriam capazes de fazer isso?

Revista Páginas de Filosofia, v. 10, n. 1, p.5-32, jan.-jun. 2021 
reação espontânea, é a formação e atribuição de nomes às coisas; ainda é um processo natural, mas é acompanhado por um senso de vantagem (utilitas) de tais distinções. É esta fase que corresponde aos gritos e ruídos dos animais ${ }^{76}$.

A origem da linguagem apresenta-se em $D R N$ como uma digressão em meio à narrativa de origem da civilização humana e aparece como importante pilar para o desenvolvimento da raça humana segundo a doutrina explicada por Lucrécio e já brevemente introduzida por Epicuro na Carta a Heródoto. Tal digressão acaba com as comparações com animais no verso 1090 e os versos seguintes retomam a descrição do comportamento dos homens primitivos com menos ênfase em sua capacidade linguística ao dar mais destaque para a organização social.

\section{A ORIGEM DA CIVILIZAÇÃo}

A partir do verso 1091, Lucrécio retorna à descrição da civilização tratando com mais detalhe sobre a descoberta do uso e do manuseio do fogo. Tal retomada se diferencia da passagem anterior, versos 101127, em que é descrito um uso do fogo para aquecer o corpo e não para cozinhar, de acordo com a explicação dada por Bailey (1962, p. 1497). Tal diferença é importante ao demonstrar um contraste entre o humano nômade que descobre, ou percebe, a existência do fogo e os benefícios que tal elemento é capaz de proporcionar, e o humano sedentário que é capaz de manusear o fogo e fazer uso dele para práticas como o cozimento dos alimentos.

0 alimento cozido e macio é um dos destaques desse excerto a seguir sobre as mudanças da civilização primitiva a partir do sedentarismo:

\footnotetext{
76 "The first is the almost physical reaction of the voice to emotions and sensations (varios linguae sonitus natura subegit mittere), which gives rise to the elementary cries of the baby.This he illustrates by the attempts of birds and animals to anticipate the use of their limbs almost before they are developed (1034-40). The second, which is developed from this spontaneous reaction, is the forming and assigning of names to things; it is still a natural process but it is accompanied by a sense of the advantage (utilitas) of such distinctions. It is this stage which corresponds to the cries and noises of the animals".
} 
indecibum coquere ac flammae mollire vapore sol docuit, quoniam mitescere multa videbant verberibus radiorum atqueaestu victa per agros. ${ }^{77}$

A possibilidade de ingerir alimentos cozidos existe apenas pela descoberta das técnicas de manuseio do fogo e tal comportamento proporcionou novos hábitos, novis rebus, v. 1106, à raça humana primitiva. Essa retomada a respeito dos costumes a partir do verso 1105 descreve mais claramente a organização da civilização, interrompida no verso 1027, ao falar brevemente sobre a figura dos reis, reges, v. 1109, e da propriedade, $\operatorname{res}^{78}$, v. 1113. A descrição dessa sociedade inicial é centrada no desenvolvimento de uma civilização governada por sábios reis e iludida pela riqueza. Segundo Bailey (1962, p. 1499) e o próprio texto lucreciano, os reis eram os homens de maiores inteligência e ensinavam técnicas de novas invenções aos demais homens. De acordo com Bailey (1962, p. 1499) ao quase parafrasear os versos de Lucrécio:

Esses homens tornaram-se reis e reuniram seu povo nas cidades, tendo o cuidado de providenciar uma cidadela para eles, na qual se protegessem contra a revolta. Eles então distribuíram rebanhos e terras aos cidadãos. $[\ldots]^{79}$

O senso de propriedade, res, v.1113, surgiu nesse contexto, segundo Lucrécio, assim como o ouro, aurumque, v. 1113, e os valores sociais passaram a ter uma nova percepção por meio dos reis. A figura do rei é descrita nessa passagem como alguém belo e honrado, como exemplificado por honorem e pulchris, v. 1114, e rico, por meio de divitioris, v. 1115. O senso de propriedade, mencionado pelo comentário de Bailey (1962, p. 1499), é a introdução da ideia de uma divisão de

\footnotetext{
${ }^{77}$ Então a cozinhar e amaciar o alimento com o calor da chama / o sol ensinou, poisviam muitas coisas amadurecerem / pelos campos, vencidas pelos golpes dos raios e pelo calor. (Tradução nossa)

${ }^{78}$ property (BAILEY, 1962, p. 1502).

79 These men became kings and gathered together their people in cities, being careful to provide a citadel for themselves, in which to protect themselves against revolt. They then distributed flocks and lands to the citizens.
} 
campos e rebanhos entre alguns homens ${ }^{80}$. A noção de propriedade leva os homens ao desenvolvimento da ambição e da inveja e à ideia de morte, de descida aos infernos, que aparece claramente como um declínio de uma sociedade que está ainda no início:

et tamen e summo, quasi fulmen, deicit ictos

invidia inter dum contemptim in Tartara taetra ${ }^{81}$

A partir do verso 1136, Lucrécio descreve o estabelecimento do que Bailey (1962, p. 1504) chama de cidade-estado e mantém a descrição centrada na figura dos reis ${ }^{82}$ e a organização social começa a ser estabelecida pouco a pouco e, ainda que a passagem da Monarquia para a República seja importante na história Romana, Lucrécio faz uma passagem sutil desse período e logo, no v. 1143, introduz a figura dos magistrados, dos tribunais e da justiça:

inde magistratum partim docuere creare

iuraque constituere, ut vellent legibus uti ${ }^{83}$.

Após tal trecho, resume Bailey (1962, p. 1504), "Mas quando as leis e tribunais foram estabelecidos, surgiu uma nova influência perturbadora na vida dos homens: o medo do castigo ${ }^{84 "}$. 0 medo é de extrema importância para a doutrina epicurista e para a transposição dela em língua latina relizada por Lucrécio. Os versos 1151-1156 introduzem tal digressão e a importante imagem do medo:

inde metus maculat poenarum praemia uitae.

circumretit enim vis atque iniuria quemque

atque unde exortast, ad eum plerumque reuertit,

\footnotetext{
${ }^{80}$ et pecudes et agros divisere a que dedere (Eles dividiram e deram rebanhos e campos)

81 e ainda do topo,como um relâmpago, joga-os feridos para baixo / a inveja com desprezo para os sujos Tártaros.

${ }^{82}$ regibus, v. 1136.

${ }^{83}$ Daí alguns ensinaram a nomear os magistrados / e a estabelecer a justiça para que desejassem obedecer às leis.

84 But when laws and law-courts were established there arose a new disturbing influence in men's lives, the fear of punishment.
} 
nec facilest placidam ac pacatam degere uitam qui uiolat factis communia foedera pacis ${ }^{85}$.

A justiça, então, é a base do início dessa civilização descrita por Lucrécio e sem a justiça é impossível viver plenamente feliz segundo a doutrina de Epicuro. Segundo o resumo de Bailey (1962, p. 1504) sobre tal digressão, "a justiça é a condição necessária para a tranquilidade mental ${ }^{86}$." Tal passagem, no entanto, não foge da questão da origem da justiça, importante ponto para o desenvolvimento do início da sociedade e da civilização. Nesse trecho há menções claras ao medo ${ }^{87}$ e à dificuldade de levar uma vida tranquila ${ }^{88}$ na ausência da justiça.

A partir do verso 1161, Lucrécio descreve a origem da religião e a relação dos homens com os deuses. A primeira explicação para a existência da religião seria inicialmente a visão que os homens receberam dos deuses, explicada pelo comentário de Bailey (1962, p.1508), e as transformavam em santuários ${ }^{89}$ e em festividades ${ }^{90}$. Nesse trecho, Lucrécio descreve a existência dos deuses e sua confirmação dada aos homens por meio das aparições durante o sono. Resume Bailey (1962, p. 1508), "As imagens que visitam os homens, principalmente durante o sono, são na verdade os simulacros que saem dos corpos dos deuses e são, portanto, uma garantia da sua existência ${ }^{91 . "}$

A outra justificativa explicitada por Lucrécio é a necessidade de explicações para os fenômenos naturais, como as estações, varia

85 Portanto, o medo dos castigos contamina as vantagens da vida. / Pois a violência e a dor envolvem-na / e na maioria das vezes e retorna a ele, do qual surgiu / nem é fácil levar uma vida calma e tranquila / para quem por suas ações viola o pacto comum de paz.

86 justice is the necessary condition of mental tranquility.

87 inde metus maculat poenarum praemia vitae. (Portanto, o medo dos castigos contamina as vantagens da vida.).

${ }^{88}$ nec facilest placidam ac pacatam degere vitam (nem é fácil levar uma vida calma e tranquila).

${ }^{89}$ qui delubra deum nova toto suscitat orbi (que ergue novos santuários dos deuses em todo).

${ }^{90}$ terrarum et festis cogit celebrare diebus, (o mundo e induz a celebrar em dias festivos.).

91 "The images which visit men, especially in sleep, are in fact the simulacra which come from the bodies of the gods and are therefore a guarantee of their existence." 
tempora annorum, v. 1184, e as mudanças dos corpos celestes, caeli rationes ordine certo, v. 1183. Os homens, então, segundo Lucrécio, não podiam conhecer as causas ${ }^{92}$ de tais fenômenos e usavam a religião, e os deuses, como justificativa.

No entanto, ambas eram um refúgio, perfugium, v.1186, pois, segundo Lucrécio e sua doutrina antiteleológica de explicação do mundo, os deuses não tomam partido nas situações humanas e os homens eram responsáveis por colocar deuses em uma posição de comando das atitudes humanas como uma espécie de refúgio:

ergo perfugium sibi habebant omnia diuis

tradere et illorum nutu facere omnia flecti ${ }^{93}$.

Nos versos finais do recorte, Lucrécio descreve a relação dos homens com a religião e o faz de uma perspectiva moral, já que procura descrever com um certo distanciamento as antigas práticas supersticiosas e como responsabilizar os deuses pelo que ocorre, v. $1887^{94}$. As práticas relacionadas aos ritos religiosos, como aproximar-se do altar, accedere ad aras, v. 1999, usar sangue de animais, sanguine quadrupedum, v. 1201-2, e fazer votos, vota, v. 1202, expressam a necessidade de um conforto com a religião e sua explicação para o mundo.

Tal descrição sobre as crenças e os deuses não foge do que é descrito por Epicuro, segundo Bailey (1962), ao narrar a importância da observação das cerimônias religiosas para a compreensão da sociedade e da raça humana. Lucrécio, no entanto, não se esquece de mencionar fenômenos naturais como os movimentos do céu e da lua, solis lunaeque viarum, v. 1206, os movimentos das estrelas, sidera candida, v. 1210.

A busca humana pela compreensão de tais fenômenos também é central no fim dessa célebre passagem e Lucrécio demonstra certa piedade, segundo Bailey (1962, p. 1513) para com essa raça humana

92 nec poterant quibus id fieret cognoscere causis. (nem podiam conhecer por quais causas isso acontecia.).

93 E então tinham um refúgio para si, tudo / colocaram sob a responsabilidade dos deuses, e supor que tudo era guiado por seu comando.

94 colocaram sob a responsabilidade dos deuses, e supor que tudo era guiado por seu comando 
em busca de respostas e segue com explicações que relacionam o temor aos deuses e as explicações dos fenômenos naturais de acordo com a doutrina de seu mestre Epicuro.

\section{Conclusão}

A obra de Lucrécio pode ser analisada e compreendida de tantas perspectivas que o termo conclusão seja, talvez, inadequado. Do ponto de vista poético e filosófico, Lucrécio é inesgotável e as análises realizadas aqui se comparam a um grão de areia ao lado de todas as perspectivas de análise permitidas e instigadas pela obra lucreciana. A intenção de Lucrécio em $D R N$ era explicar os fenômenos do mundo e da natureza por meio da doutrina epicurista e o faz de maneira clara e por meio da poesia épica didática totalmente inserida na tradição grega e romana.

O Livro 5 é uma das 6 etapas de $D R N$ e se concentra na explicação do mundo terreno e dos fenômenos naturais que compõem as vidas vegetal e animal, sendo a vida humana parte intrínseca da animal e analisada também enquanto sociedade. A descrição que Lucrécio apresenta a respeito da raça humana por meio de seus hexâmetros está sempre amparada pelas imagens de animais, seja pela comparação de um comportamento infantil, agressivo e até mesmo sexual. A Idade do Ouro, canônica nas descrições antigas sobre a origem da sociedade, como em Hesíodo, não é completamente harmônica de acordo com a descrição lucreciana e os homens tendem habitualmente a não conviver de modo tranquilo com as feras.

A raça humana é descrita de modo harmônico com a jovem natureza, uma Natura que era capaz de produzir diversos alimentos de modo espontâneo, mas com o decorrer do texto de Lucrécio o comportamento dos seres humanos primitivos muda pouco a pouco. A raça humana aprende a se organizar de forma sedentária e passa a dominar as diversas técnicas de trabalho no campo, passa a consumir um alimento não mais cru, mas cozido ao dominar a técnica do manuseio do fogo e tudo passa a impactar na organização social dos primeiros humanos sedentários.

De acordo com os hexâmetros que compõem $D R N$, o uso de roupas também foi de extrema importância, e, além disso, as organizações sociais 
foram pouco a pouco se tornando mais unidas por meio das figuras dos reis e dos governantes. A base social passou, então, a ser a justiça e o medo da punição. A complexificação dessa organização social é explicada também pela importância das descobertas técnicas da navegação e da religião, sendo as cerimônias dessa última uma importante base para uma mudança social desde os primórdios, que, segundo Lucrécio, impactava inclusive o período contemporâneo ao poeta.

A sucinta análise do recorte do texto lucreciano aqui exposta se deteve na expressão poética usada pelo poeta ao narrar a matéria filosófica epicurista na origem da linguagem e da sociedade, todavia, como anteriormente pontuado, ainda muitas outras análises cabem a essa obra. A poesia de Lucrecio não se limita à métrica, espraiandose, sobretudo, na matéria filosófica e ainda com um vasto leque de possibilidade a ser explorado.

Citando Calvino novamente, porém, agora seu artigo: Por que ler os clássicos: "Dizem-se clássicos aqueles livros que constituem uma riqueza para quem os tenha lido e amado; mas constituem uma riqueza não menor para quem se reserva a sorte de lê-los pela primeira vez nas melhores condições para apreciá-los." (CALVINO, 1993, p.1 0). A leitura da obra de Lucrécio é, no entanto, uma constante (re)descoberta, já que demonstra ainda novas perspectivas de compreensão dos fazeres poético e filosófico dos antigos.

Cientificamente superada, a teoria da linguagem e da civilização exposta nos versos lucrecianos segue intacta na tradição literária e filosófica pela inovação que oferece ao ser escrita em um tempo distante, em palavras novas, em versos e em complexidade que é capaz de ensinar ainda hoje poética e filosoficamente fatos novos, inesperados, inéditos e inovadores.

\section{REFERÊNCIAS}

BAILEY, Cyril (Org.). De rerum natura libri sex. Edited with prolegomena, critical apparatus, translation and commentary. v. 3. Great Britain: Oxonii e Typographeo Clarendoniano, 1962.

CALVINO, Italo. Seis propostas para o próximo milênio. Tradução: Ivo Barroso. Companhia das Letras: São Paulo, 19090. Por que ler os clássicos. Tradução: Nilson Moulin. Companhia das Letras: São Paulo, 1993.

Revista Páginas de Filosofia, v. 10, n. 1, p.5-32, jan.-jun. 2021 
CAMPBELL, Gordon (Org.). Lucretius on Creation and Evolution. A Commentaryon De Rerum Natura Book Five, Lines 772-1104. Oxford: Oxford UniversityPress, 2003. COSTA, C.D.N. (Org.). De rerum natura V. . Oxford: Clarendon Press, 1984.

DEUFERT, Marcus. De rerum natura. Berlim: De Gruyter, 2019.

FABBRI, Tebaldo (Org.). Templa Serena: antologia dal de rerum natura. A cura di Tebaldo Fabbri. Firenze: La Nuova Italia, 1997.

MAIA JUNIOR, Juvino Alves; VIEIRA, Hermes Orígenes Duarte; ALMEIDA, Felipe dos Santos. De Rerum natura: Livro I, de Tito Lucretius Carus, Ideia, João Pessoa, 2016.

MILANESE, Guido (Org.). La natura delle cose. Tradução: Guido Milanese. 2014. Milano: Mondadori, 2014.

OLIVA NETO, João Angelo. Dos gêneros da poesia antiga e sua tradução em português. Tese (Livre Docência). São Paulo, 2013.

PIAZZI, Lisa (Org.). Le leggi dell'universo: la natura, libro I. A cura di Lisa Piazzi con testo a fronte. Venezia: Marsilio, 2011.

PESSANHA, José Américo Motta (Org.). Os pensadores: Epicuro, Lucrécio, Cícero, Sêneca, Marco Aurélio. Tradução e notas: Agostinho da Silva, Amador Cisneiros, Giulio Davide Leoni, Jaime Bruna.. São Paulo: Abril Cultural, 1985.

SMITH, Martin Ferguson (Com.). On the nature of things. Tradução: Martin Fergunson Smith. Oxford: Hackett Publishing Company, 2001.TREZZA, Gaetano (Com.). Il poema della natura: antologia con riassunti delle parte omesse. Milano: Carlo Signorelli, 1994.

Revista Páginas de Filosofia, v. 10, n. 1, p.5-32, jan.-jun. 2021 